\title{
Lateral Torsional Buckling of Steel Beams under Transverse Impact Loading
}

\author{
Wenna Zhang $\mathbb{D},{ }^{1,2}$ Feng Liu, ${ }^{3}$ and Feng Xi $\mathbb{D}^{2}$ \\ ${ }^{1}$ Research Institute of Structural Engineering and Disaster Reduction, Tongji University, Shanghai 200092, China \\ ${ }^{2}$ School of Civil Engineering, Shandong Jianzhu University, Jinan 250101, China \\ ${ }^{3}$ Shandong University of Science and Technology, \\ Shandong Provincial Key Laboratory of Civil Engineering Disaster Prevention and Mitigation, Qingdao 266590, China
}

Correspondence should be addressed to Feng Xi; xifeng@sdjzu.edu.cn

Received 12 July 2017; Revised 8 November 2017; Accepted 6 December 2017

Academic Editor: Hugo Rodrigues

Copyright (C) 2018 Wenna Zhang et al. This is an open access article distributed under the Creative Commons Attribution License, which permits unrestricted use, distribution, and reproduction in any medium, provided the original work is properly cited.

\begin{abstract}
This study employs experiments and numerical simulation to analyze the dynamic response of steel beams under huge-mass impact. Results show that lateral torsional buckling (LTB) occurs for a narrow rectangular cross-section steel beam under transverse impact. The experiments were simulated using LS-DYNA. The numerical simulation is in good agreement with experimental results, thus indicating that the LTB phenomenon is the real tendency of steel beams under impact. Meanwhile, the study shows that LSDYNA can readily predict the LTB of steel beams. A numerical simulation on the dynamic response of $\mathrm{H}$-shaped cross-section steel beams under huge-mass impact is conducted to determine the LTB behavior. The phenomenon of dynamic LTB is illustrated by displacement, strain, and deformation of $\mathrm{H}$-shaped steel beams. Thereafter, a parametric study is conducted to investigate the effects of initial impact velocity and momentum on LTB. The LTB of H-shaped cross-section steel beams under transverse impact is primarily dependent on the level of impact kinetic energy, whereas impact momentum has a minor effect on LTB mode.
\end{abstract}

\section{Introduction}

Beams and columns of special steel frame structures should withstand not only normal design load but also explosion, impact, collision, fire, and other extreme loads during the period of service. Hence, the dynamic response and failure behavior of steel members under these extreme loads need to be studied. In fact, explosion and shock have often been associated with fire. Therefore, the effect of the interaction between the structure under impact load and fire needs to be investigated.

Stability is a potent issue in the design of steel structures. Bad stability of steel components may cause serious structural failure. Lateral torsional buckling of a component is a very common type of instability that needs further investigation [1]. Lateral torsional buckling (overall instability) of steel beams under static loads can be described as follows [2]: when steel beams, without lateral support in the net span, are subjected to a certain value of transverse load or moment about the major-axis, a large lateral displacement $u$ and twist angle $\theta$ occur as shown in Figure 1. Then, the beam loses its carrying capacity. Obviously, out-of-plane buckling analysis is more difficult than analysis of in-plane bending buckling. However, a number of studies have been conducted based on elastic buckling theory, particularly experimental studies and theoretical analysis [3] on lateral torsional buckling of steel beams under static load. Yang et al. carried out experimental tests and numerical simulations on lateral torsional buckling behavior of singly symmetric I-beams fabricated from Q460GJ steel $[4,5]$. Their results showed that steel beams developed lateral torsional buckling under concentrated point loads at the mid-span. Hence, local buckling was not observed. Karmazínová et al. [6] studied the lateral flexural-torsional buckling of steel sigmacross-section beams with web holes. Their study conclusions became the background of the supplements to specified provisions for the design of steel structures. Kala and Valeš [7] examined a hot-rolled steel I-beam subjected to lateral torsional buckling (LTB) due to bending moment and obtained the stochastic effects of initial imperfection and residual 


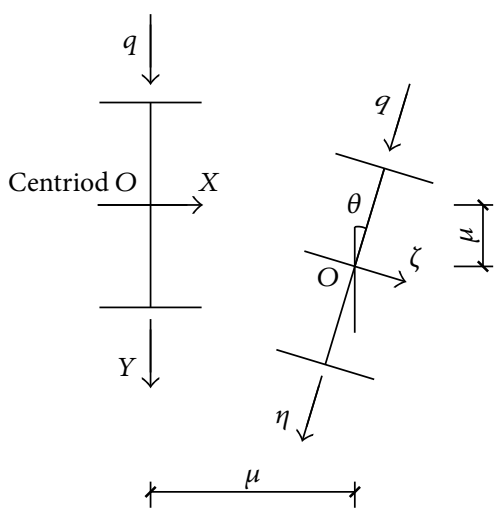

FIGURE 1: LTB of H-shaped steel beams.

stress on the resistance of the investigated steel beam. The development of numerical methods, such as finite element (FE), has facilitated research on lateral torsional buckling of steel beams from experimental studies to numerical analysis [8-10]. Moreover, research on the fire resistance of steel structures has made great progress [11]. Lateral torsional buckling problem of steel beams under fire has been given considerable attention [12-14]. This problem is due to the substantial number of the torsional buckling modes of steel beam during fire accidents. A steel structure can endure fire for a very long time. Hence, analysis of structures under fire can be regarded as a static problem. When structures are subjected to fire, elevated temperature causes degradation of material properties and triggers plastic deformation of the structure. Thus, elastic buckling theory is not suitable anymore. Therefore, numerical simulation is an effective research method to deal with inelastic buckling problems. For example, Vila Real et al. $[15,16]$ performed a numerical study and proposed a design curve for the LTB of steel beams. Yin and Wang [17] have numerically investigated the effects of several design factors on lateral torsional buckling bending moment resistance of steel I-beams submitted to nonuniform temperature distribution. Couto et al. [18] studied the lateral torsional buckling of beams with slender cross-sections in the case of fire using a numerical method.

Whether LTB behavior occurs when steel beam is subjected to the combined action of impact and fire loading is difficult to determine because of the complexity of two-load interaction effects. In addition, LTB occurrence on the steel beam when it is only subjected to impact is difficult to investigate because impact load affects the plastic buckling of beams whereas the inertial effect may delay or avoid plastic buckling. On one hand, steel is a rate sensitive material meaning that the yield strength of steel can be improved because of the strain rate effect. Hence, the strain rate effect of steel may lead to the occurrence of elastic LTB. These complex factors hinder the full understanding of LTB behavior of steel beams under impact. In recent years, several studies were conducted on the dynamic response of steel members under impact. The drop weight impact test of clamped steel beams struck transversely at the center by a mass with a rectangular indenter was conducted by Villavicencio and Guedes Soares [19] to define the proper boundary conditions of impacted beams. Wang et al. [20] studied the dynamic behavior of steel beams with fin-plate connections subjected to falling floor impact loads. The results show that steel beams show dynamic behaviors under a certain impact energy with varying impact masses and velocities. A higher impact velocity can slightly improve the energy dissipation rate. Steel beams develop different impact resistances while impact loads are applied at various locations. Al-Thairy and Wang [21] examined the behavior and failure modes of axially compressed steel columns subject to transverse impact by a rigid mass at varying impact speeds and locations. Ning and Zhao [22, 23] completed the experimental study on the stability of aluminum alloy cantilever high beams under cylinder head impact. However, studies on LTB of steel beams under impact load are lacking.

Above all, systemic research on LTB of steel beams under impact load is necessary. This article is a preliminary attempt of related studies. This paper presents the experimental results of the LTB of rectangular section steel beams under drop hammer impact. Afterwards, the LTB behavior of rectangular section and $\mathrm{H}$-shaped steel beams under impact is discussed.

\section{Experimental Test Introduction}

The drop weight test of steel beams was carried out by setting up a DHR9401 drop hammer test machine. The overall height of the DHR9401 drop hammer test machine is about $13.47 \mathrm{~m}$ above the floor and its impact velocity is up to $15.70 \mathrm{~m} / \mathrm{s}$. Figure 2 shows the components of the drop hammer test machine. The impact hammer comprises several main components. The first piece is a toughened flat head which is $80 \mathrm{~mm}$ long and $30 \mathrm{~mm}$ thick and made from high-strength chromium 15 (64HRC) as shown in Figure 3. The second component of the striker is the weight element. This component contains the main mass of the striker and delivers a variety of striker weights from 2 to $250 \mathrm{~kg}$. The third part of the striker is load cells. The overall weight of the impact hammer is $57.8 \mathrm{~kg}$ and can be raised to the required height to produce varied impact velocities (up to $15.7 \mathrm{~m} / \mathrm{s}$ ) and energies [24].

Rolled steel plates (Q235) were selected to make the specimens. The specimens were classified according to the thickness of the beam: \#A: $5 \times 50 \times 1250 \mathrm{~mm}^{3}$, \#B: $5 \times 70 \times$ $1250 \mathrm{~mm}^{3}$, and $\# \mathrm{C}: 5 \times 100 \times 1250 \mathrm{~mm}^{3}$. The effective spans of steel beams were 500, 750, and $1000 \mathrm{~mm}$, as shown in Figure 4.

Table 1 shows the dimensions of steel beams. The constraints of steel beams were implemented by the length of the reserved. Two supports were fixed on both ends of the experimental platforms. Bolts flank the support side to implement lateral fixation. The rotation constraint was fixed by a steel cover plate as shown in Figure 5. The material properties of the specimens are determined from standard static tensile coupon tests which have been carried out by a CM5105A computer-controlled electronic omnipotence test machine. The experiment was repeated 3 times and the data averaged. Figure 6 shows the stress-strain curve of the steel. 


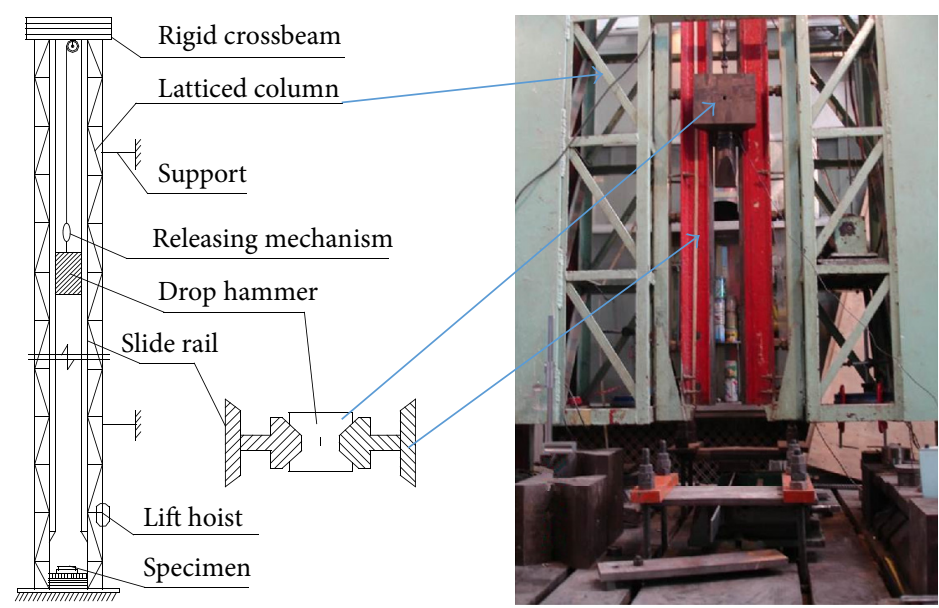

FIGURE 2: DHR9401 drop hammer test machine.

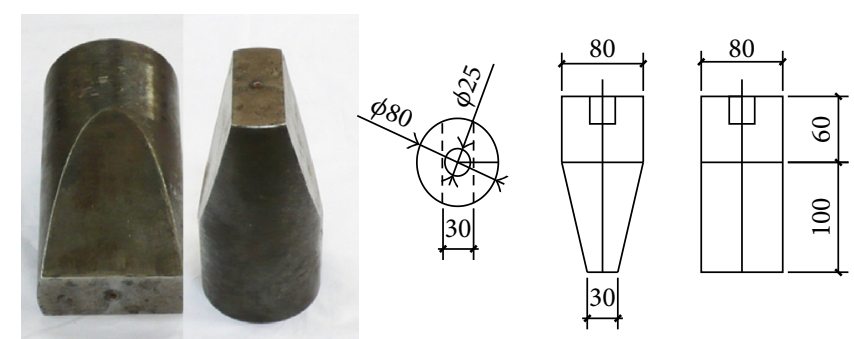

FIGURE 3: Shape and size of drop hammer.

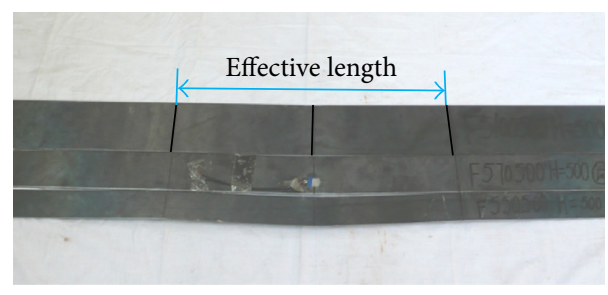

FIgURE 4: Test specimens.

The modulus of elasticity and yield stress of the steel beams are $185 \mathrm{GPa}$ and $315 \mathrm{MPa}$, respectively.

\section{Experimental Test Results}

3.1. General Results. In these tests, the ultimate deformation modes and lateral and vertical deflections on mid-span of beams were recorded. Then, the influence of section properties, height-width ratio, length-height ratio, and impact velocity on the ultimate deformation modes was studied. Table 2 shows the results of the test specimens, where $H_{I}$ is the impact height, $D_{V}$ is the vertical displacement, $D_{L}$ is the lateral displacement, and $V_{0}$ is the initial impact velocity.

In Table 2, it is noticed that the lateral and vertical deflections increase with the increase in impact velocity. It is also observed that the deformation of beams is influenced by the height-width and length-height ratio. The length-height ratio varied at a range of 10 and 20 of specimens A1-3 and A3-1, while the impact velocity is $3.13 \mathrm{~m} / \mathrm{s}$ and height-width ratio is 10 . The lateral displacements of specimens A1-3 and A3-1 are 0.9 and $21.78 \mathrm{~mm}$, respectively. The vertical displacements of specimens A1-3 and A3-1 are 9.82 and $20.4 \mathrm{~mm}$. Thus, the deformation of the beams is proportional to the length-height ratio. The height-width ratio varies at a range of 10,14 , and 20 of specimens A3-3, B3-2, and C3-2 whereas the impact velocity is $5.42 \mathrm{~m} / \mathrm{s}$ and length-height ratio is 20 . The lateral displacements of specimens A3-3, B3-2, and C3-2 are $75.1,51.3$, and $17.6 \mathrm{~mm}$, respectively. The vertical displacements of specimens A3-3, B3-2, and C3-2 are 94.4, 46.36, and $18.14 \mathrm{~mm}$, respectively. Thus, the deformation of the beams is inversely proportional to the height-width ratio. Moreover, the ultimate deformation modes of beams are influenced by section properties, height-width and length-height ratios, and impact velocity.

3.2. Ultimate Deformation Modes. Figure 7 shows the ultimate deformation modes of specimen \#A1 for various velocities. Specimen A1-1 has noticeable in-plane deformation without the lateral displacements on twists. The local deformation of specimens A1-2 and A1-3 has been found without the LTB. When impact velocity reaches $4.43 \mathrm{~m} / \mathrm{s}$, in specimens A1-4 and A1-5, the LTB occurs. At the same time, specimen A1-5 has an risen deformation. The experimental 
TABLE 1: Specifications of test specimens.

\begin{tabular}{|c|c|c|c|}
\hline $\begin{array}{l}\text { Specimen } \\
\text { number }\end{array}$ & $\begin{array}{c}\text { Geometry size } \\
(B \times H \times L) \\
\left(\mathrm{mm}^{3}\right)\end{array}$ & $\begin{array}{c}\text { Height-width ratio } \\
\alpha=H / B\end{array}$ & $\begin{array}{c}\text { Length-height ratio } \\
\qquad \beta=L / H\end{array}$ \\
\hline \#A1 & $5 \times 50 \times 500$ & 10 & 10 \\
\hline \#A2 & $5 \times 50 \times 750$ & 10 & 15 \\
\hline \#A3 & $5 \times 50 \times 1000$ & 10 & 20 \\
\hline \#B1 & $5 \times 70 \times 500$ & 14 & 10 \\
\hline \#B3 & $5 \times 70 \times 1000$ & 14 & 20 \\
\hline$\# \mathrm{C} 1$ & $5 \times 100 \times 500$ & 20 & 10 \\
\hline \#C2 & $5 \times 100 \times 750$ & 20 & 15 \\
\hline \#C3 & $5 \times 100 \times 1000$ & 20 & 20 \\
\hline
\end{tabular}
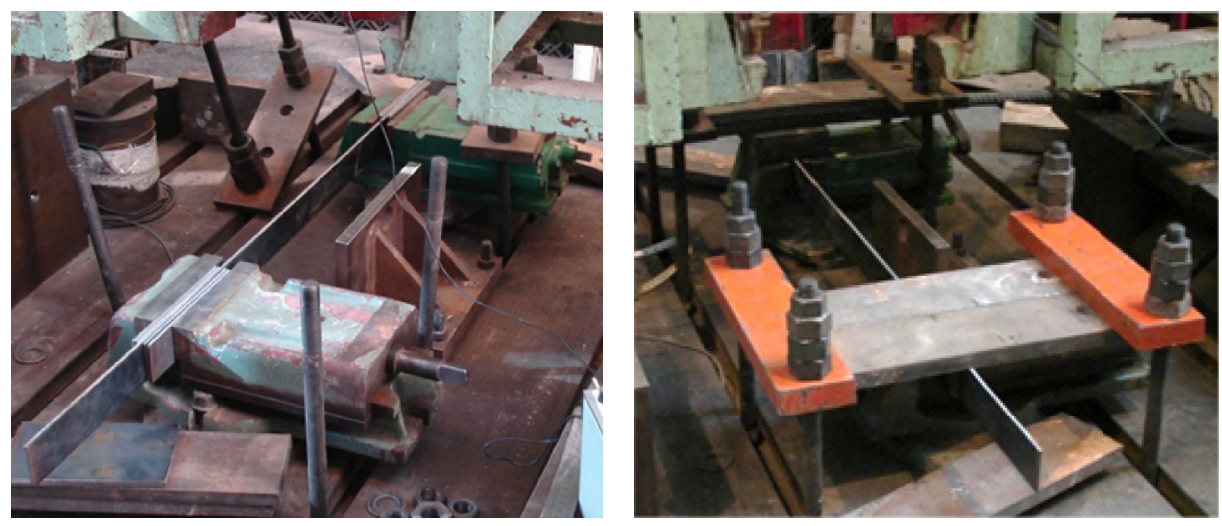

FIGURE 5: Boundary conditions of the experiment.

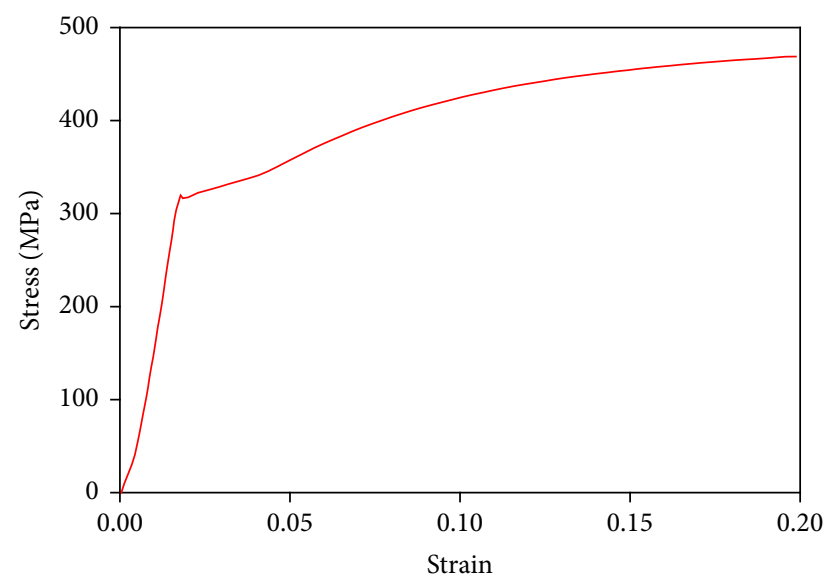

FIGURE 6: Stress-strain curve.

results show that LTB occurs for rectangular section steel beams under transverse impact. This LTB phenomenon is mainly influenced by the impact velocity. It can be seen that the LTB critical velocity of A1 must be between 3.13 and $4.43 \mathrm{~m} / \mathrm{s}$.

Figure 8 shows the ultimate deformation modes of specimen \#A2 with different velocities of $4.43,5.42$, and $6.26 \mathrm{~m} / \mathrm{s}$. Specimens A2-1, A2-2, and A2-3 all show LTB behavior. In the meantime, the deformation of \#A2 increases with the increase of the impact velocity. Figure 9 shows the ultimate deformation modes of specimen \#A3. Specimen \#A3 also has the LTB behavior. The LTB deformation of \#A3-1 is mainly the out-of-plane bending deformation. The torsion deformation of \#A3-1 is relatively small. From the ultimate deformation modes of A1-4, A2-1, and A3-2, it can be observed that the length-height ratio has a considerable influence on LTB modes.

Figure 10 shows the ultimate deformation modes of specimen \#B1 for various velocities. When the impact velocity is $3.13 \mathrm{~m} / \mathrm{s}$, specimen B1-1 has an in-plane deformation without the lateral displacements on twists. Specimen B1-2 has an outplane deformation with an impact velocity of $4.43 \mathrm{~m} / \mathrm{s}$. When the impact velocity reaches 5.42 and $6.26 \mathrm{~m} / \mathrm{s}$, specimens B13 and B1-4 have the behavior of LTB with flexural buckling as the main deformation. When the impact velocity reaches 7 and $7.67 \mathrm{~m} / \mathrm{s}$, specimens B1-5 and B1-6, respectively, have different LTB modes with torsional deformation. Once again, it can be observed that the impact velocity has a considerable influence on the deformation of beams. Figure 11 shows the ultimate deformation modes of specimen \#B3 with different velocities. It can be seen that specimen B3-1 presents the flexural-torsional buckling behavior with flexural buckling as the main deformation. When the impact velocity reaches 5.42 and $6.26 \mathrm{~m} / \mathrm{s}$, the beam presents various LTB modes. 
TABLE 2: Numbers and test results of specimens.

\begin{tabular}{|c|c|c|c|c|c|c|c|}
\hline Specimen number & $\begin{array}{c}H_{I} \\
(\mathrm{~m})\end{array}$ & $\alpha$ & $\beta$ & $\begin{array}{c}V_{0} \\
(\mathrm{~m} / \mathrm{s})\end{array}$ & $D_{V}(\mathrm{~mm})$ & $D_{L}(\mathrm{~mm})$ & Deformation mode \\
\hline \#A1-1 & 0.2 & 10 & 10 & 1.98 & 4.10 & 0.98 & In-plane bending \\
\hline \#A1-2 & 0.3 & 10 & 10 & 2.42 & 5.86 & 0.80 & Local deformation \\
\hline \#A1-3 & 0.5 & 10 & 10 & 3.13 & 9.82 & 0.90 & Local deformation \\
\hline \#A1-4 & 1.0 & 10 & 10 & 4.43 & 21.74 & 9.50 & LTB \\
\hline \#A1-5 & 2.0 & 10 & 10 & 6.26 & 46.10 & 20.88 & LTB \\
\hline \#A2-1 & 1.0 & 10 & 15 & 4.43 & 45.46 & 47.56 & LTB \\
\hline \#A2-2 & 1.5 & 10 & 15 & 5.42 & 84.03 & 61.60 & LTB \\
\hline \#A2-3 & 2.0 & 10 & 15 & 6.26 & 117.8 & 59.40 & LTB \\
\hline \#A3-1 & 0.5 & 10 & 20 & 3.13 & 20.40 & 21.78 & LTB \\
\hline \#A3-2 & 1.0 & 10 & 20 & 4.43 & 42.48 & 36.10 & LTB \\
\hline \#A3-3 & 1.5 & 10 & 20 & 5.42 & 94.40 & 75.10 & LTB \\
\hline \#B1-1 & 0.5 & 14 & 10 & 3.13 & 5.36 & - & In-plane bending \\
\hline \#B1-2 & 1.0 & 14 & 10 & 4.43 & 5.52 & 0.80 & Local deformation \\
\hline \#B1-3 & 1.5 & 14 & 10 & 5.42 & 9.72 & 0.80 & LTB \\
\hline \#B1-4 & 2.0 & 14 & 10 & 6.26 & 22.16 & 6.66 & LTB \\
\hline \#B1-5 & 2.5 & 14 & 10 & 7.00 & 33.60 & - & LTB \\
\hline \#B1-6 & 3.0 & 14 & 10 & 7.76 & 41.60 & - & LTB \\
\hline \#B3-1 & 1.0 & 14 & 20 & 4.43 & 24.20 & 21.30 & LTB \\
\hline \#B3-2 & 1.5 & 14 & 20 & 5.42 & 46.36 & 51.30 & LTB \\
\hline \#B3-3 & 2.0 & 14 & 20 & 6.26 & 80.10 & 67.70 & LTB \\
\hline \#C1-1 & 0.5 & 20 & 10 & 3.13 & 3.22 & - & LTB \\
\hline \#C1-2 & 1.0 & 20 & 10 & 4.43 & 4.97 & - & LTB \\
\hline \#C1-3 & 2.0 & 20 & 10 & 6.26 & 10.26 & - & LTB \\
\hline \#C1-4 & 2.5 & 20 & 10 & 7.00 & 11.92 & 1.60 & LTB \\
\hline \#C2-1 & 1.0 & 20 & 15 & 4.43 & 7.10 & 3.40 & LTB \\
\hline \#C2-2 & 1.5 & 20 & 15 & 5.42 & 10.94 & 3.40 & LTB \\
\hline \#C2-3 & 2.0 & 20 & 15 & 6.26 & 16.56 & 2.06 & LTB \\
\hline \#C3-1 & 1.0 & 20 & 20 & 4.43 & 10.44 & 9.72 & LTB \\
\hline \#C3-2 & 1.5 & 20 & 20 & 5.42 & 18.14 & 17.60 & LTB \\
\hline \#C3-3 & 2.0 & 20 & 20 & 6.26 & 26.14 & 4.90 & LTB \\
\hline
\end{tabular}

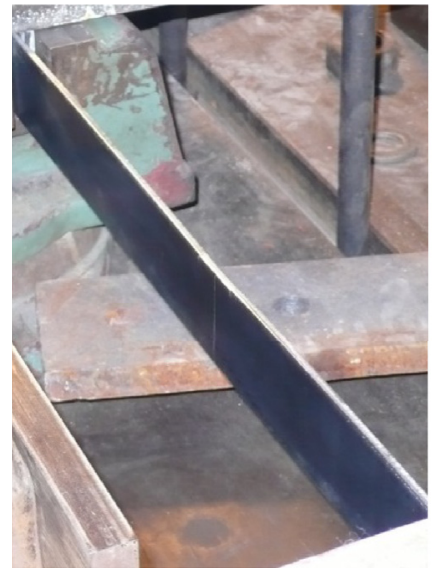

$V_{0}=1.98 \mathrm{~m} / \mathrm{s}$

\#A1-1 (0.2 m)
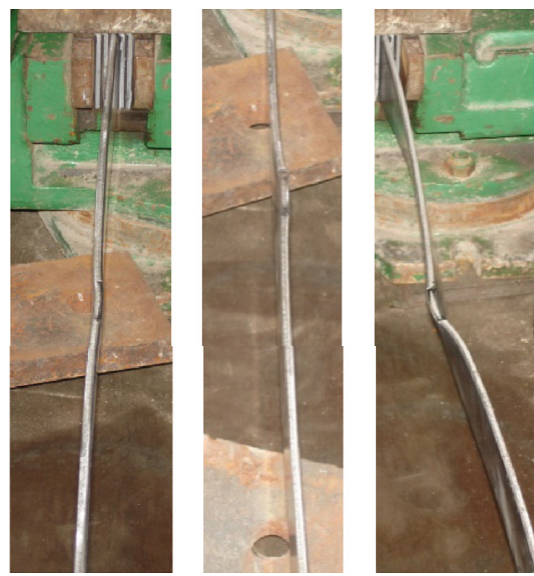

$V_{0}=2.42 \mathrm{~m} / \mathrm{s} \quad V_{0}=3.13 \mathrm{~m} / \mathrm{s} \quad V_{0}=4.43 \mathrm{~m} / \mathrm{s}$ \#A1-2 (0.3 m) \#A1-3 (0.5 m) \#A1-4 (1 m)

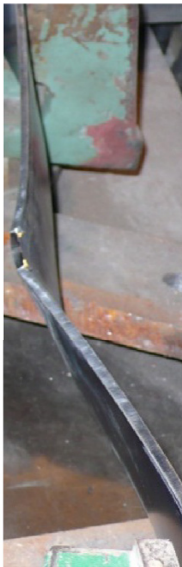

$V_{0}=6.26 \mathrm{~m} / \mathrm{s}$ \#A1-5 (2 m)

Figure 7: Deformation modes of \#A1 $(\alpha=10, \beta=10)$. 


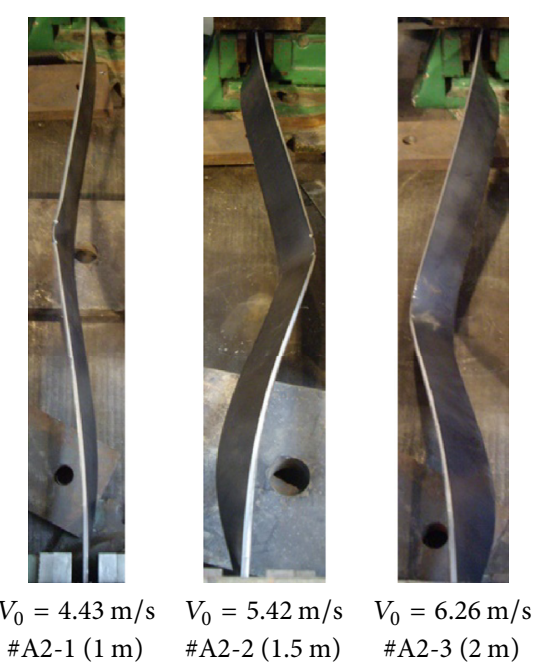

Figure 8: Deformation modes of \#A2 $(\alpha=10, \beta=15)$.

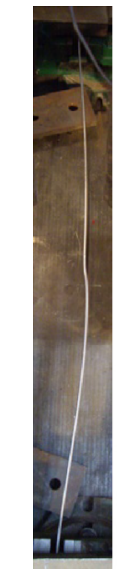

$V_{0}=3.13 \mathrm{~m} / \mathrm{s}$ \#A3-1 (0.5 m)

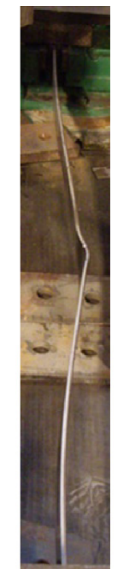

$V_{0}=4.43 \mathrm{~m} / \mathrm{s}$ \#A3-2 (1 m)

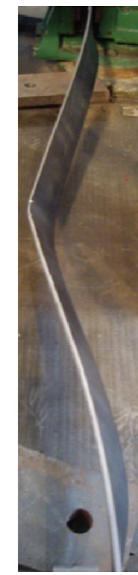

$V_{0}=5.42 \mathrm{~m} / \mathrm{s}$ \#A3-3 (1.5 m)

Figure 9: Deformation modes of \#A3 $(\alpha=10, \beta=20)$.

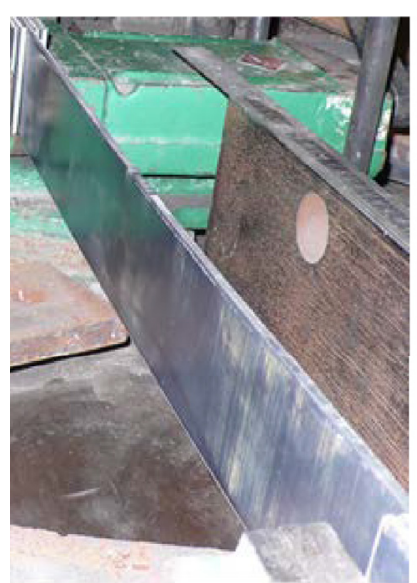

$V_{0}=3.13 \mathrm{~m} / \mathrm{s}$

\#B1-1 (0.5 m)

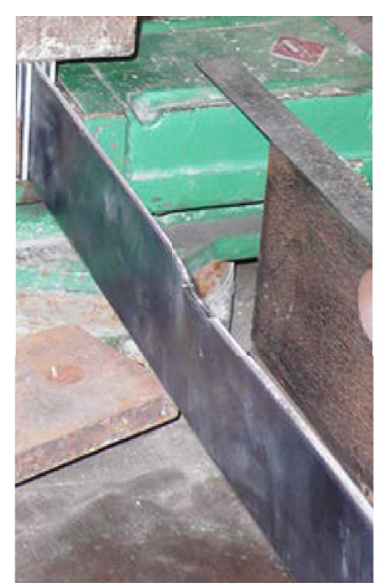

$V_{0}=4.43 \mathrm{~m} / \mathrm{s}$

\#B1-2 (1 m)

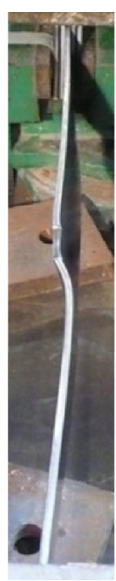

$V_{0}=5.42 \mathrm{~m} / \mathrm{s}$ \#B1-3 (1.5 m)

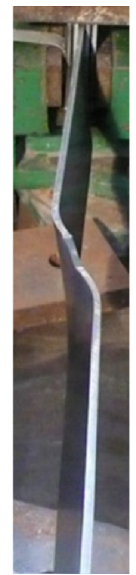

$V_{0}=6.26 \mathrm{~m} / \mathrm{s}$ \#B1-4 (2 m)

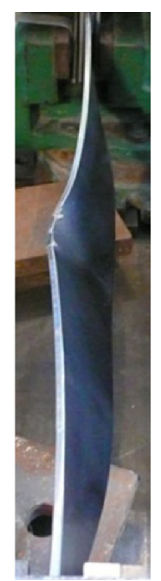

$V_{0}=7 \mathrm{~m} / \mathrm{s}$ \#B1-5 (2.5 m)

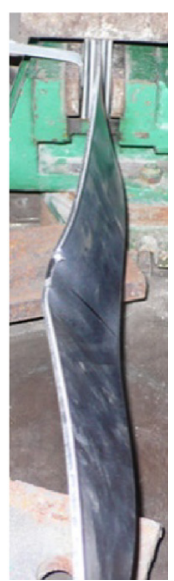

$V_{0}=7.76 \mathrm{~m} / \mathrm{s}$ \#B1-6 (3 m)

Figure 10: Deformation modes of \#B1 $(\alpha=14, \beta=10)$. 


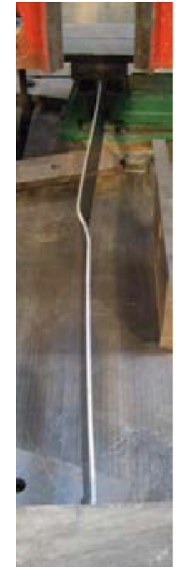

$V_{0}=4.43 \mathrm{~m} / \mathrm{s}$

\#B3-1 (1 m)

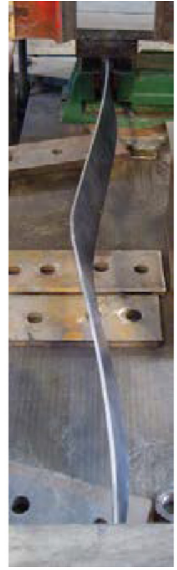
\#B3-2 (1.5 m)
$V_{0}=5.42 \mathrm{~m} / \mathrm{s}$

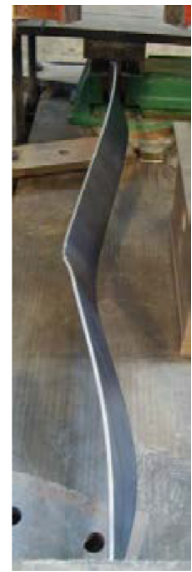

$V_{0}=6.26 \mathrm{~m} / \mathrm{s}$ \#B3-3 (2 m)
FIGURE 11: Deformation modes of \#B3 $(\alpha=14, \beta=20)$.

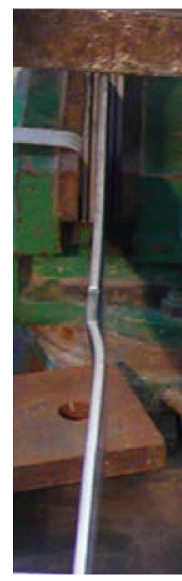

$V_{0}=3.13 \mathrm{~m} / \mathrm{s} \quad V_{0}=4.43 \mathrm{~m} / \mathrm{s}$ \#C1-1 (0.5 m)

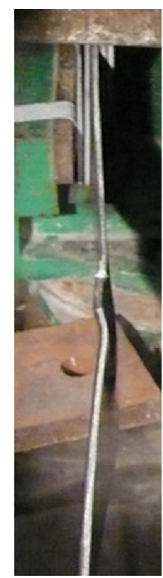

\#C1-2 (1 m)

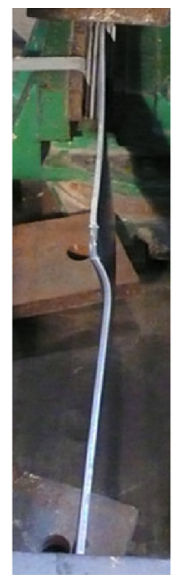

$V_{0}=6.26 \mathrm{~m} / \mathrm{s}$ \#C1-3 (2 m)

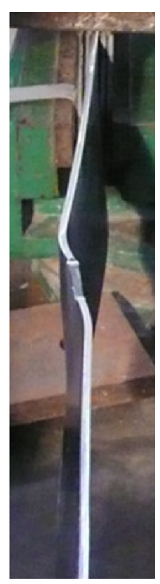

$V_{0}=7.00 \mathrm{~m} / \mathrm{s}$ \#C1-4 (2.5 m)
FIGURE 12: Deformation modes of \#C1 $(\alpha=20, \beta=10)$.

Figures 12, 13, and 14 show the ultimate deformation modes of specimens \#C1, \#C2, and \#C3 with different velocities. Flexural-torsional buckling noticeably occurs for specimens $\# \mathrm{C} 1, \# \mathrm{C} 2$, and $\# \mathrm{C} 3$ at different impact velocities. At the same impact kinetic energy, specimens B3 and C3 have different LTB modes. This difference is caused by the variation of section heights between B3 and C3. The LTB of the steel beams with smaller section height is similar to the firstorder static buckling mode. With the increase of the section height, the torsional stiffness of the steel beam increases and the possibility of first-order static buckling-like LTB mode decreases. As a result, the steel beams with larger section height are more likely to behave the second-order buckling mode.

The abovementioned results show that rectangular section steel beams under transverse impact can lead to LTB behavior. The LTB mode of rectangular section steel beams

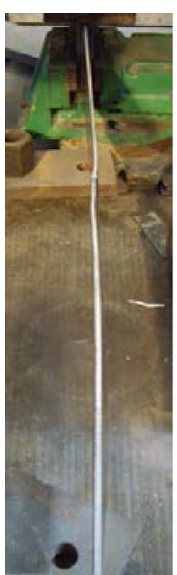

$V_{0}=4.43 \mathrm{~m} / \mathrm{s}$ \#C2-1 (1 m)

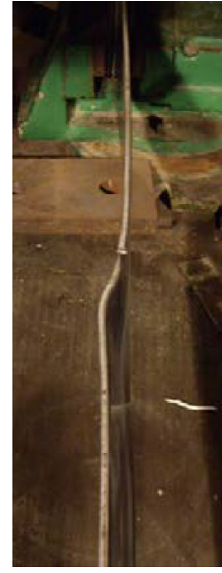

$V_{0}=5.42 \mathrm{~m} / \mathrm{s}$ \#C2-2 (1.5 m)

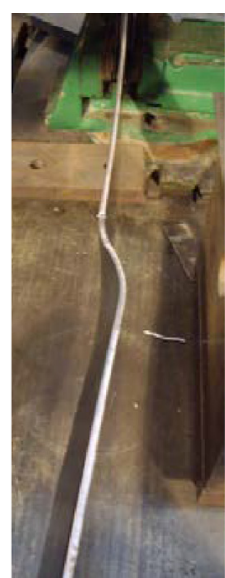

$V_{0}=6.26 \mathrm{~m} / \mathrm{s}$ \#C2-3 (2 m)
Figure 13: Deformation modes of \#C2 $(\alpha=20, \beta=15)$.

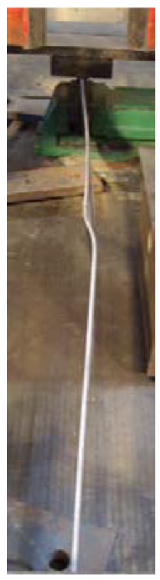

$V_{0}=4.43 \mathrm{~m} / \mathrm{s}$ \#C3-1 (1 m)

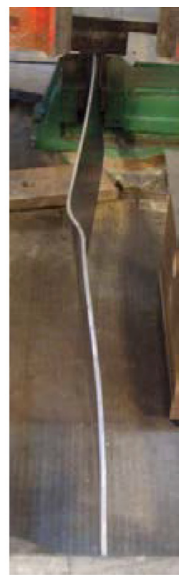

$V_{0}=5.42 \mathrm{~m} / \mathrm{s}$ \#C3-2 (1.5 m)

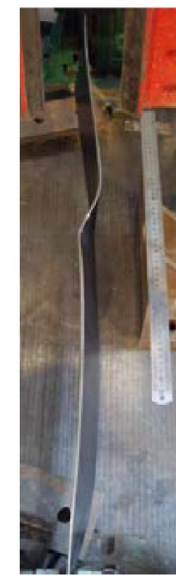

$V_{0}=6.26 \mathrm{~m} / \mathrm{s}$

\#C3-3 (2 m)
FIGURE 14: Deformation modes of \#C3 $(\alpha=20, \beta=20)$.

under impact is not a single pattern and depends on the geometry of the specimen.

\section{Numerical Simulation}

4.1. Finite Element Model. Numerical simulation is carried out by finite element code LS-DYNA and element SOLID164 was used to simulate the solid beam and drop hammer. SOLID164 [25] is used for the 3D modeling of solid structures. The element is defined by eight nodes having the following degrees of freedom at each node: translations, velocities, and accelerations in the nodal $x, y$, and $z$ directions. This element is used in explicit dynamic analyses. In this paper, the elastic-perfectly plastic model is adopted for the numerical analysis using the Material Type 3 [26] of LS-DYNA. This model is suited for modeling isotropic and kinematic hardening plasticity with the option of including rate effects. As a type of strain rate sensitive material, steel 


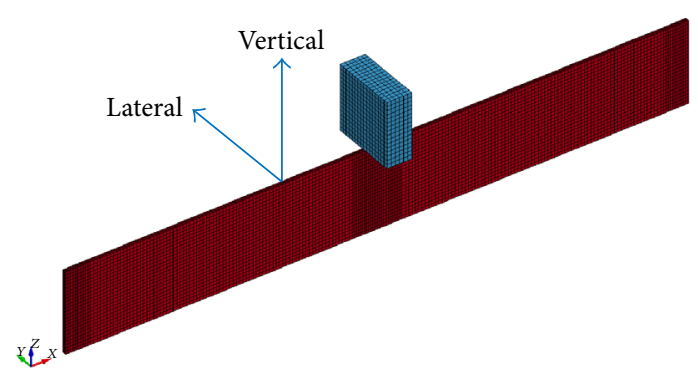

FIGURE 15: Finite element model.

has a considerably high yield stress under high strain rates. When structures are subjected to impact loads, strain rate effect has a considerable influence on the dynamic behavior and damage [20]. The strain rate effects are described by employing the Cowper-Symonds [27] equation with material parameters of $=40 \mathrm{~s}^{-1}, n=5$. The relationship between yield stress and strain rate is expressed in the following equation:

$$
\sigma_{y}=\sigma_{0}\left[1+\left(\frac{\dot{\varepsilon}_{p}}{D}\right)^{1 / n}\right],
$$

where $\sigma_{y}$ and $\sigma_{0}$ are the dynamic and static yield stress of the material, respectively, and $\varepsilon_{p}$ is the equivalent plastic strain rate. The values for $E$ and $\sigma_{0}$ have been chosen to be consistent with those given in the previous section. The density of steel is $7,850 \mathrm{~kg} / \mathrm{m}^{3}$ while the Poisson ratio is 0.3 . The values of elastic modulus, yield strength, and tangent modulus are similar to those in Figure 3 which features the stress-strain curve. Since the current study aims to investigate the behavior of steel beams under transverse impact load, the emphasis is on the beam rather than the drop hammer. Therefore, only a brief description is given on the drop hammer which is assumed to be a rigid cuboid with dimensions of $30 \times 80 \times 80 \mathrm{~mm}^{3}$. To increase the calculation precision and efficiency, the impact location and nearby supports are simulated in a fine mesh whereas a coarse mesh is used elsewhere. The drop hammer is modeled as a nondeformable solid object. The number of elements has no effect on the calculation precision. Hence, the drop hammer is simulated in a coarse mesh and divided into 1,536 eight-node hexahedrons. A steel beam is divided into 8,216 eight-node hexahedrons. The maximum mesh size of the solid elements is $15 \mathrm{~mm}$ as shown in Figure 15. An initial imperfection is generally applied to a structure model in buckling analysis. The buckling mode under impact load should be the superposition of static buckling modes whereas the percentage of the low order buckling mode is comparatively high. For the low-speed impact problem in this paper, buckling should be close to the first-order mode. Therefore, in the analysis, the initial imperfection has the same shape as the first-order mode for bending vibration with amplitude of $L / 1000$, where $L$ is the beam span.

In this paper, the boundary conditions of beam are simulated by restraining the $x, y$, and $z$ direction node displacement in both ends of the steel beam constrained area. The impact hammer moves only in the vertical direction while other displacement and angle directions are restrained.
In the numerical simulation analysis, the impact energies are given by setting the different initial velocities of the drop hammer. During the impact experiment, the contact interface is formed using the impact hammer and steel surface. When two solid bodies touch, contact stresses are transmitted across their common interface. This contact interface is able to pass the force but is not allowed to penetrate. To model the contact behavior between the front surface of the impact hammer and top surface of beams, the automatic surface-to-surface constraint algorithm with friction is used, where the friction coefficients are introduced to simulate the friction forces transmitted across the contact interface.

4.2. Comparison of Simulation and Experiment Results. The numerical simulation on the experiment of steel beams \#A1, \#B3, and \#C2 under the drop hammer was carried out using the previously mentioned FE technique. Then, the simulation and experiment results are compared. Figure 16 shows both results of deformation mode of \#A1. It is noticed that, under different impact velocities, the deformation behavior of the steel beams is different. When $V_{0}=1.98 \mathrm{~m} / \mathrm{s}$, the experimental and numerical results show that the beams do not produce LTB, but only the in-plane bending deformation. When $V_{0}=3.13 \mathrm{~m} / \mathrm{s}$, local deformation occurs in the midspan and the steel beams do not produce overall buckling yet. However, at the initial impact velocity of $4.43 \mathrm{~m} / \mathrm{s}$, the experiment and numerical results all show that the beam produces out-of-plane buckling and mainly lateral bending deformation. When impact velocity is up to $6.26 \mathrm{~m} / \mathrm{s}$, the LTB behavior of beams is presented by experimental and numerical results and mainly torsional deformation. Figures 17 and 18 show the experimental and numerical results of the deformation mode of $\# \mathrm{~B} 3$ and $\# \mathrm{C} 2$, respectively. It is noticed that the numerical simulation results are basically consistent with the experiment results under varied impact velocities. Table 3 shows the lateral and vertical deflections at mid-span of beams under different impact velocities. It is noticed that the results of the numerical simulation are in good agreement with the experimental results. Thus, the validity and reliability of the simulation method used in the paper are verified. At the same time, it is observed that the numerical simulation method can predict the LTB of steel beams.

\section{Numerical Simulation on the LTB of H-Shaped Steel Beams under Transverse Impact}

Nowadays, H-shaped steel beams are commonly used as important bearing component of steel structures. Steel beams and columns may fail under a lateral torsional buckling mode under impact and lead to the collapse of the structure. Therefore, studying the buckling tendency of $\mathrm{H}$-shaped steel members under impact is increasingly important [28]. In this section, the numerical simulation analysis on the dynamic response of $\mathrm{H}$-shaped steel beams is carried out using the numerical simulation method which has been verified. The LTB behavior of $\mathrm{H}$-shaped steel beams is studied based on the characteristics of lateral displacement and strain. In 
TABLE 3: Comparisons of deflection on mid-span from tests and numerical simulations.

\begin{tabular}{|c|c|c|c|c|c|c|}
\hline \multirow{2}{*}{ Specimen number } & \multirow{2}{*}{ Constraint } & \multirow{2}{*}{$\begin{array}{c}V_{0} \\
(\mathrm{~m} / \mathrm{s})\end{array}$} & \multicolumn{2}{|c|}{$D_{L}(\mathrm{~mm})$} & \multicolumn{2}{|c|}{$D_{V}(\mathrm{~mm})$} \\
\hline & & & Experiment & Simulation & Experiment & Simulation \\
\hline \#A1-1 & Fixed-fixed & 1.98 & 0.90 & 0.98 & 4.10 & 3.10 \\
\hline \#A1-3 & Fixed-fixed & 3.13 & 0.90 & 0.88 & 9.80 & 8.40 \\
\hline \#A1-4 & Fixed-fixed & 4.43 & 9.80 & 9.80 & 21.70 & 16.80 \\
\hline \#A1-5 & Fixed-fixed & 6.26 & 20.90 & 26.90 & 46.10 & 45.20 \\
\hline \#B3-1 & Fixed-fixed & 4.43 & 24.20 & 18.20 & 21.30 & 19.50 \\
\hline \#B3-2 & Fixed-fixed & 5.42 & 46.36 & 31.70 & 51.30 & 35.30 \\
\hline \#B3-3 & Fixed-fixed & 6.26 & 80.10 & 43.70 & 67.70 & 44.40 \\
\hline \#C2-1 & Fixed-fixed & 4.43 & 7.10 & 5.09 & 3.40 & 4.08 \\
\hline \#C2-2 & Fixed-fixed & 5.42 & 10.94 & 9.53 & 3.40 & 3.00 \\
\hline \#C2-3 & Fixed-fixed & 6.26 & 16.56 & 12.60 & 2.06 & 1.53 \\
\hline
\end{tabular}

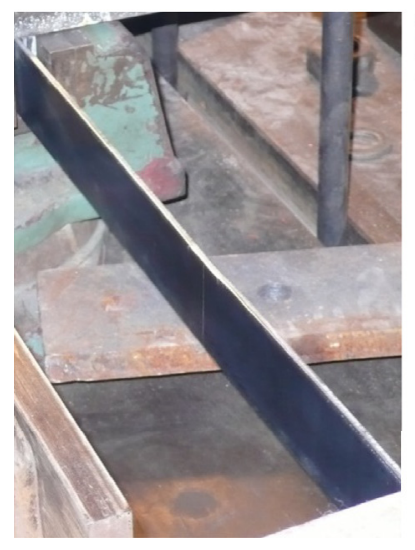

$V_{0}=1.98 \mathrm{~m} / \mathrm{s}$

\#A1-1 (0.2 m)
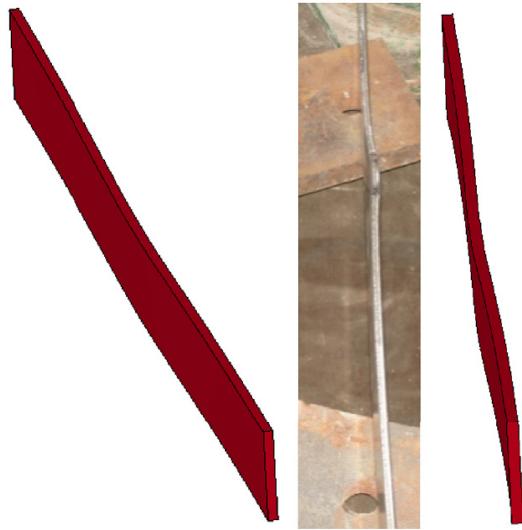

$V_{0}=3.13 \mathrm{~m} / \mathrm{s}$

\#A1-3 (0.5 m)
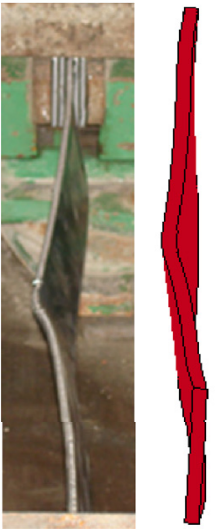

$V_{0}=4.43 \mathrm{~m} / \mathrm{s}$

\#A1-4 (1 m)
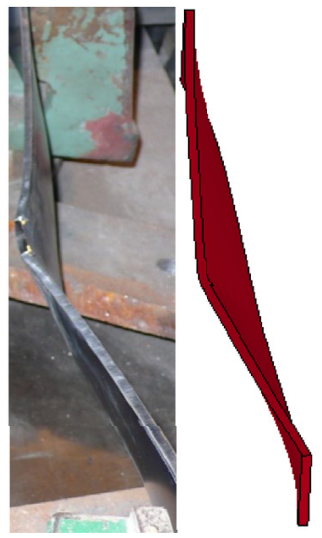

$V_{0}=6.26 \mathrm{~m} / \mathrm{s}$

\#A1-5 (2 m)

FIgURE 16: Comparison with \#A1.

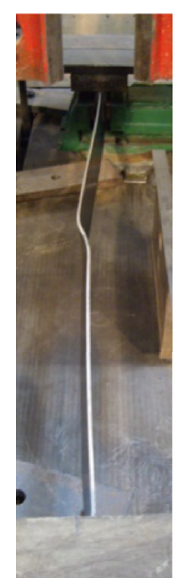

$V_{0}=4.43 \mathrm{~m} / \mathrm{s}$ \#B3-1 (1 m)
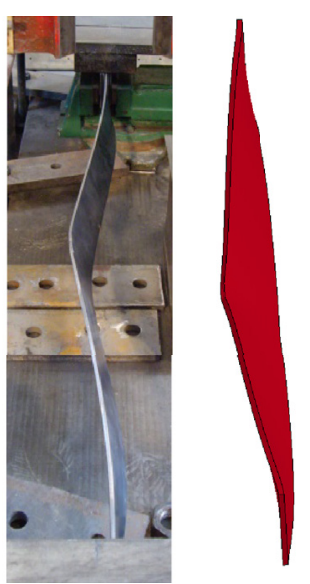

$V_{0}=5.42 \mathrm{~m} / \mathrm{s}$

\#B3-2 (1.5 m)
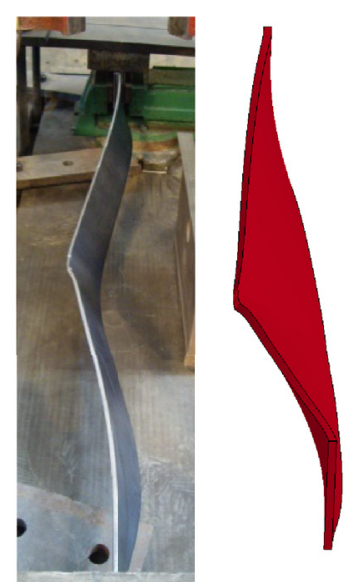

$V_{0}=6.26 \mathrm{~m} / \mathrm{s}$

\#B3-3 (2 m)

Figure 17: Comparison with \#B3. 


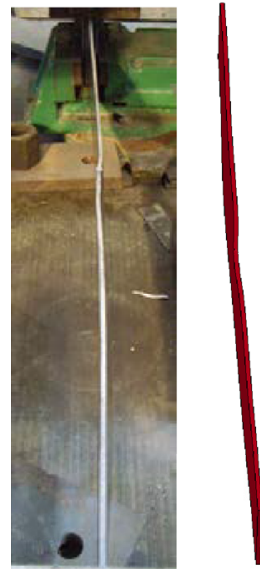

$V_{0}=4.43 \mathrm{~m} / \mathrm{s}$

\#C2-1 (1 m)

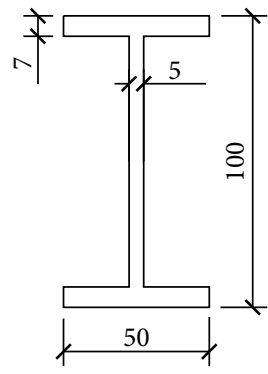

FIGURE 19: Cross-section of a beam.

this research, the following important parameters have been identified for parametric study: impact velocity and impact momentum.

5.1. Numerical Model. Figure 19 shows the dimension of an $\mathrm{H}$-shaped cross-section; the span of the beam is $1.5 \mathrm{~m}$. The beam is fixed on both ends. Steel is assumed to be grade Q235 while the steel modulus of elasticity and yield strength are assumed to be $206 \mathrm{GPa}$ and $235 \mathrm{MPa}$, respectively. The impact energies are given by setting different impact heights. The mass of the drop hammer is assumed to be $200 \mathrm{~kg}$ in this research.

Explicit dynamical analysis is used to simulate the dynamic response of the beams under impact. The simulation model comprises the following mesh and material properties.

Strain rate effect: Cowper-Symonds equation with $D=$ $40.4 \mathrm{~s}^{-1}, n=5$, and mesh: steel beam is divided into 22,716 eight-node hexahedrons (SOLID164) and the maximum mesh size of the solid elements is $15 \mathrm{~mm}$ as shown in Figure 20. Since the current study aims to investigate the behavior and failure modes of $\mathrm{H}$-shaped steel beams under transverse impact load, the emphasis is on the beam rather than the drop hammer. Hence, only one drop hammer geometry with a dimension of $30 \times 80 \times 120 \mathrm{~mm}^{3}$ is considered. In the numerical simulation analysis, the density of the drop

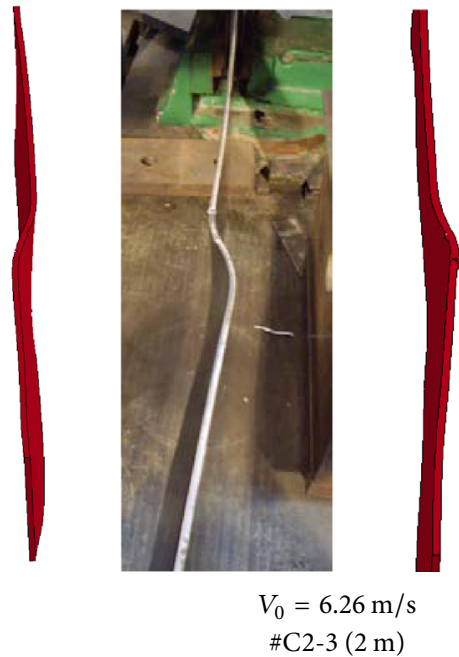

\#C2-3 (2 m)

FIGURE 18: Comparison with \#C2.

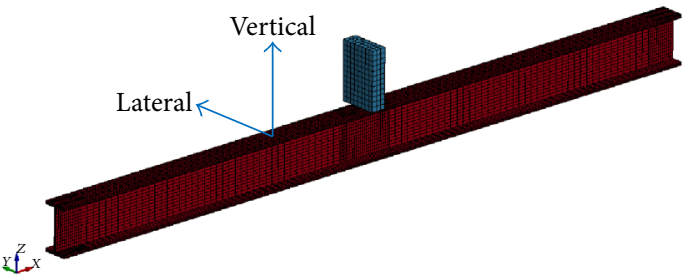

FIgURE 20: Finite element model.

hammer is adjusted to obtain the required mass. The drop hammer is divided into 1,536 eight-node hexahedrons. The initial distance between the striking tip of the drop hammer and top surface of $\mathrm{H}$-shaped steel beam is set at $5 \mathrm{~mm}$. In this section, the initial imperfection has the same shape as the first mode for bending vibration with an amplitude of $L / 1000$, where $L$ is the beam span.

5.2. Numerical Results. In the current section, the numerical results of the $\mathrm{H}$-shaped steel beam under transverse impact, such as the entire process of the impact, residual deformation of beam, and time history curves of strain, will be discussed. Output data curves of displacement during the simulation are at a $3,750 \mathrm{~Hz}$ sampling rate.

5.2.1. Plastic Deformation of Beam. Figure 21 shows the residual deformation of the $\mathrm{H}$-shaped steel beam under transverse impact when the initial impact velocity is $6 \mathrm{~m} / \mathrm{s}$. It is noticed from Figure 21 that an LTB behavior is observed while the maximum of the lateral deformation is produced mid-span. At the same time, a local deformation of the beam flange is observed at the location of the steel beam top flange in contact with the impact hammer.

5.2.2. Impact Process. Figure 22 illustrates the whole dynamic response of $\mathrm{H}$-shaped steel beams under transverse impact. It is observed that the lateral displacement of the beam increases 


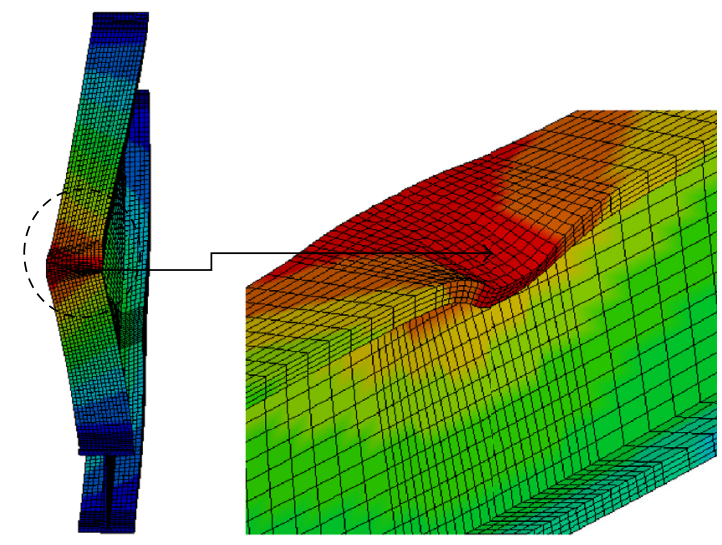

FIgURE 21: Plastic deformation of beam.
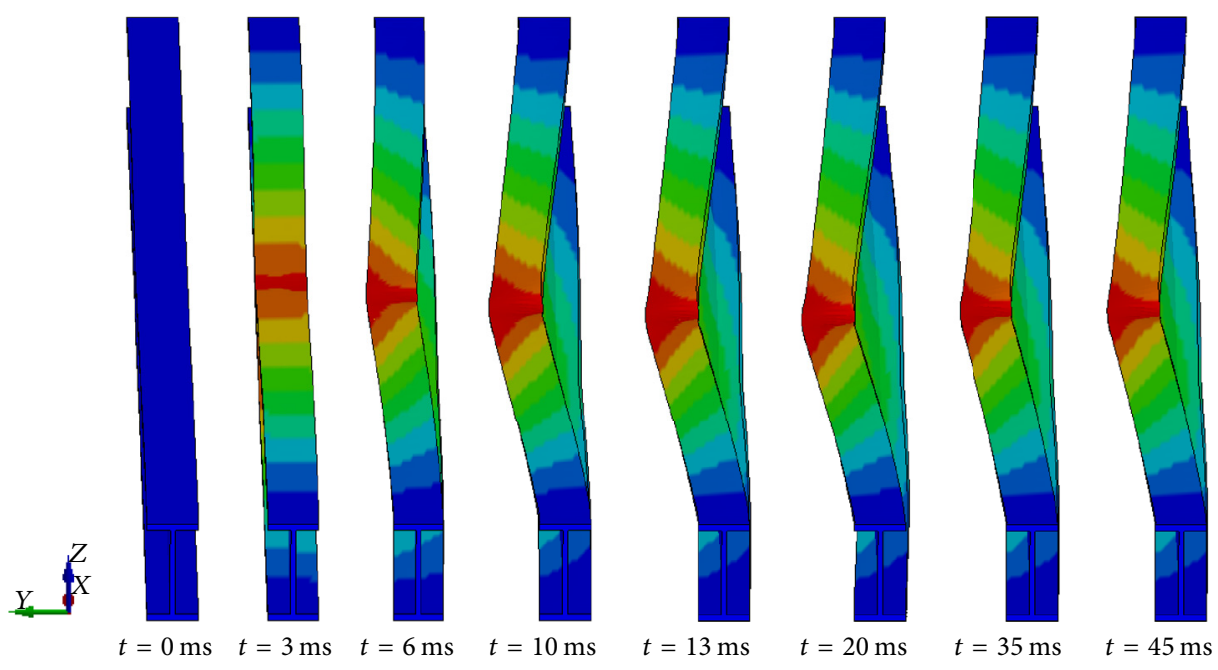

Figure 22: Impact process.
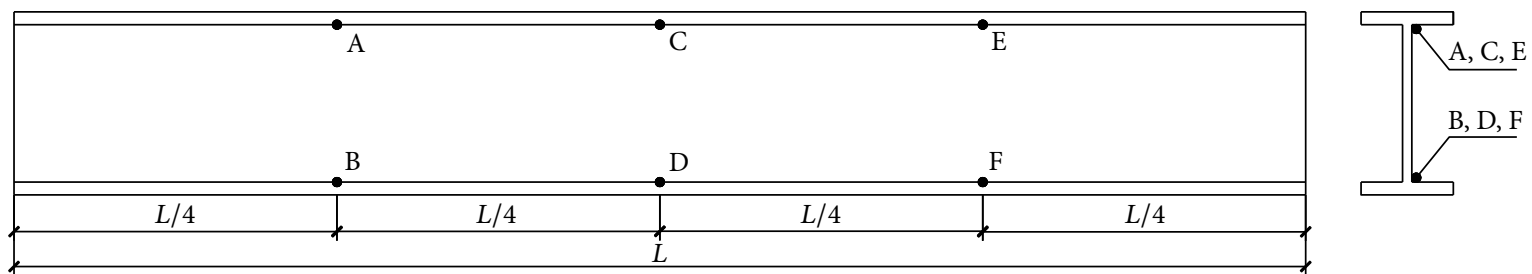

FIGURE 23: Location of nodes.

with the increase in contact time of the drop hammer and beam. The maximum lateral displacement occurs at an impact time of $13 \mathrm{~ms}$, which includes elastic and plastic deformation. With the movement of the drop hammer and beam, the elastic deformation of beam gradually recovers and the whole displacement of the beam is reduced until the elastic deformation of beam fully recovers. The plastic deformation of the $\mathrm{H}$-shaped steel beam occurs at $35 \mathrm{~ms}$.

5.2.3. Plastic Deformation of Beam. In the current section, the lateral and vertical displacements-time history curves at different nodes of the steel beam are studied. Figure 23 shows the location of the nodes and all points belong to the beam web.

The lateral displacement-time history curves at different nodes of the steel beam are given as shown in Figure 24. It is observed that the lateral displacement of nodes from various locations of beam is different. The residual lateral displacements of nodes $\mathrm{A}$ and $\mathrm{E}$ are $15.4 \mathrm{~mm}$ whereas node $\mathrm{C}$ is at $36.7 \mathrm{~mm}$. The difference of the residual lateral displacements on nodes $\mathrm{A}$ and $\mathrm{C}$ indicates that the beam produces lateral bending deformation. The residual lateral displacements of 


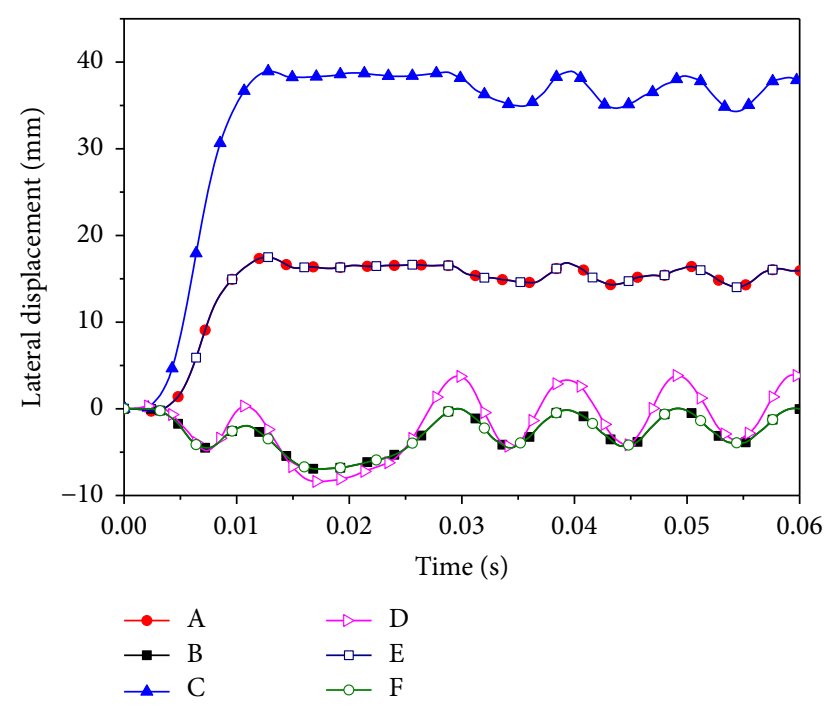

FIGURE 24: Lateral displacement-time history curve.

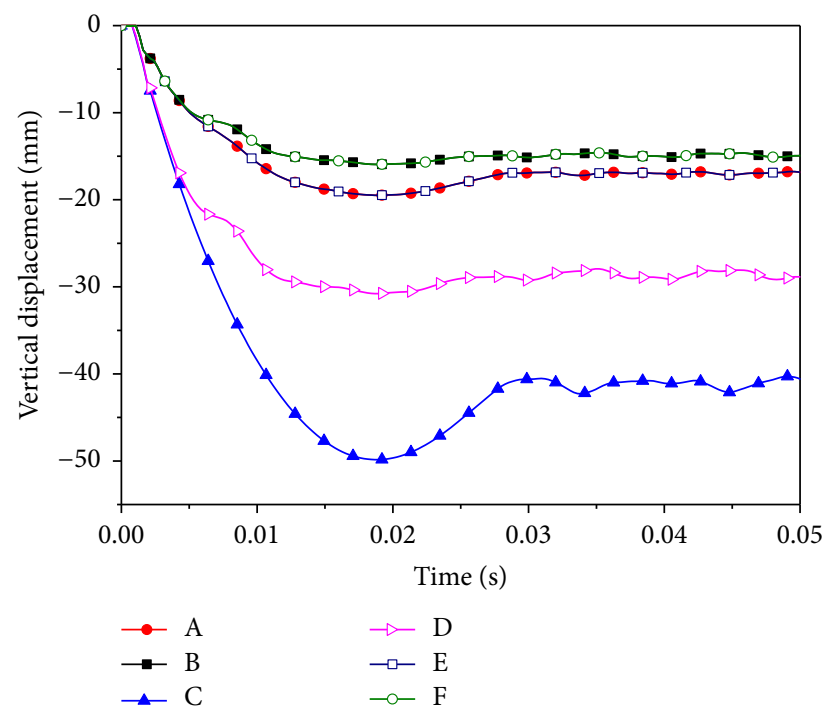

FIgURE 25: Vertical displacement-time history curve.

nodes $\mathrm{A}, \mathrm{C}$, and $\mathrm{E}$ are greater than zero and corresponding displacements of nodes $\mathrm{B}, \mathrm{D}$, and $\mathrm{F}$ are less than zero. This shows that the out-of-plane torsion deformation of the steel beam is produced during movement. From the abovementioned discussion, the $\mathrm{H}$-shaped steel beam under transverse impact produces the LTB phenomenon.

Figure 25 shows that the residual vertical displacements of nodes C and D are 41.2 and $28.3 \mathrm{~mm}$, respectively. From the difference of the residual vertical displacement, it can be seen that the $\mathrm{H}$-shaped steel beam under transverse impact occurs in not only in-plane bending deformation but torsional deformation. Figure 25 also demonstrates that the residual vertical displacements of nodes $A$ and $B$ agree with nodes $\mathrm{E}$ and $\mathrm{F}$, respectively. This agreement is brought by the constraint and symmetrical load of specimen. Hence,

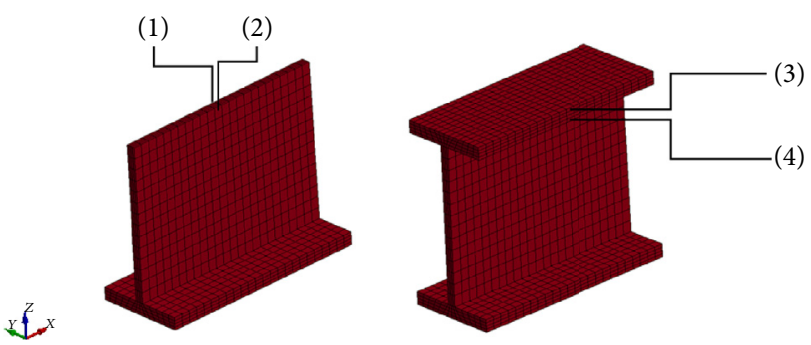

FIGURE 26: Symmetrical elements of web and flange.

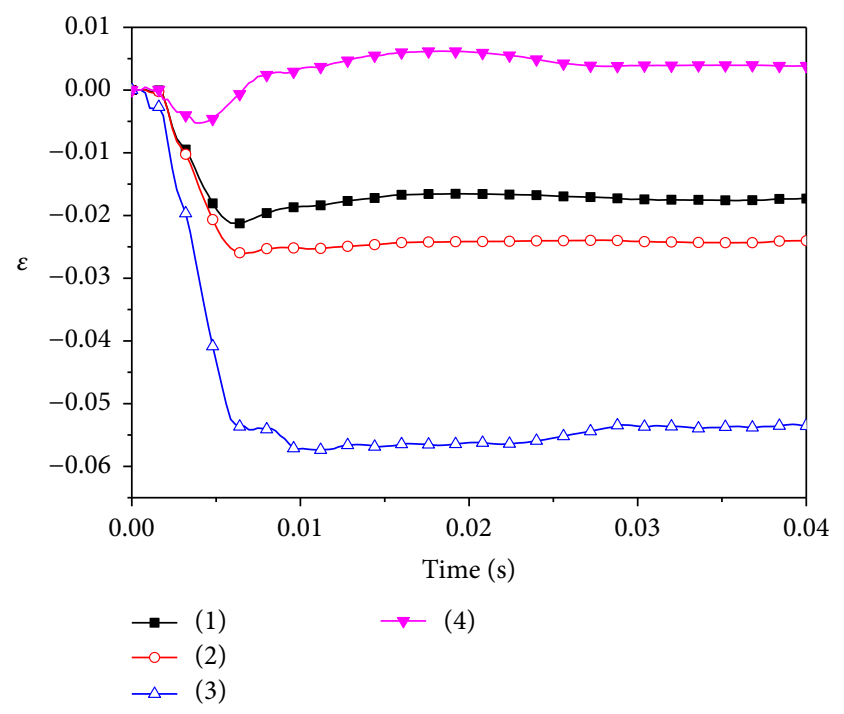

FIGURE 27: Strain-time history curves.

the residual vertical displacement-time history curves of the beam are also symmetrical.

5.2.4. Strain-Time History Curves. Figure 27 presents the strain-time history curves for the two groups of symmetrical elements from the mid-span of the H-shaped steel beam web and flange, respectively. Figure 26 shows the locations of symmetrical elements. Figure 27 shows that the strain of the two symmetrical elements of the beam web is coincident during 0 to $4 \mathrm{~ms}$. This behavior indicates that the $\mathrm{H}$-shaped steel beam web moves in a plane at the beginning and then produces an out-of-plane movement. Figure 27 also shows that the strain-time curves of the two symmetrical elements on the beam flange are different at the beginning of the movement. This result indicates that the $\mathrm{H}$-shaped steel beam flange produces out-of-plane movement first. This is because the drop hammer comes into contact with the beam flange directly and leads the top flange to produce the buckling first.

Based on the above discussion, it can be found that the $\mathrm{H}$-shaped steel beams under transverse impact can cause the LTB behavior.

5.3. Effects of Different Drop Hammers. In this research, the following two important parameters have been identified for parametric study: impact velocity and impact momentum. 
TABLE 4: Analytical results of momentum effects.

\begin{tabular}{|c|c|c|c|c|c|c|c|}
\hline Case & Mass (kg) & $K_{I}(\mathrm{~J})$ & $M_{I}(\mathrm{Ns})$ & $V_{0}(\mathrm{~m} / \mathrm{s})$ & $D_{V}(\mathrm{~mm})$ & $T_{C}(\mathrm{~ms})$ & Deformation mode \\
\hline 1 & 100 & 3600 & 850 & 8.5 & 39.2 & 19.3 & LTB \\
\hline 2 & 200 & 3600 & 1200 & 6.0 & 40.8 & 28.8 & LTB \\
\hline 3 & 300 & 3600 & 1470 & 4.9 & 42.4 & 35.8 & LTB \\
\hline
\end{tabular}

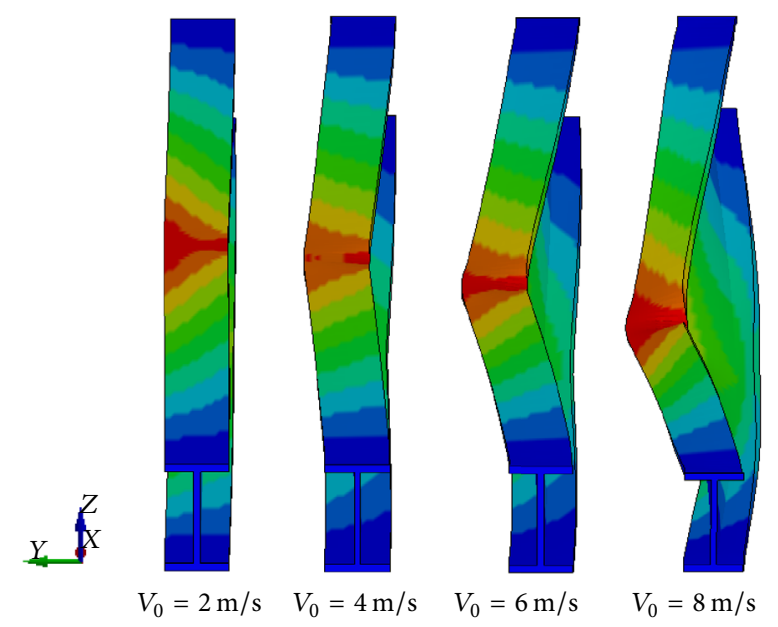

Figure 28: Plastic deformation of beam under different impact velocities.

This section will present numerical simulation results to help understand the effects of these design parameters.

5.3.1. Effects of Impact Velocity. In this section, the dynamic responses of $\mathrm{H}$-shaped steel beams are studied at different impact velocities where the initial impact velocity $V_{0}$ is 2,4 , 6 , and $8 \mathrm{~m} / \mathrm{s}$.

Figure 28 presents the plastic deformation of the $\mathrm{H}$ shaped steel beam under different impact velocities. When $V_{0}=2 \mathrm{~m} / \mathrm{s}$, the $\mathrm{H}$-shaped steel beam only occurs in inplane bending deformation whereas LTB behavior is not observed. When $V_{0}=4,6$, and $8 \mathrm{~m} / \mathrm{s}$, it is observed that the $\mathrm{H}$-shaped steel beam produces the LTB accompanied by the local deformation of the beam flange. Figure 29 shows the impact response for the lateral displacement of mid-span of the $\mathrm{H}$-shaped steel beam under different impact velocities. It can be seen that the plastic deformation of $\mathrm{H}$-shaped steel beam increases with the increase of initial impact velocity. Hence, with the increase in initial impact velocity, the $\mathrm{H}$ shaped steel beams are more sensitive to the LTB.

\subsubsection{Impact Momentum Effects on the LTB of H-Shaped Steel} Beams. In this section, the dynamic response analyses on $\mathrm{H}$ shaped steel beam subjected to transverse impact are carried out using three cases. The three cases have different masses of drop hammer, impact velocities, and same kinetic energy of $3600 \mathrm{~J}$. Table 4 shows the three sets of conditions and impact momentum effects on the LTB of $\mathrm{H}$-shaped steel beams, where $K_{I}$ is the impact kinetic energy of the drop hammer, $M_{I}$ is the impact momentum of the drop hammer, and $T_{C}$ is the contact time.

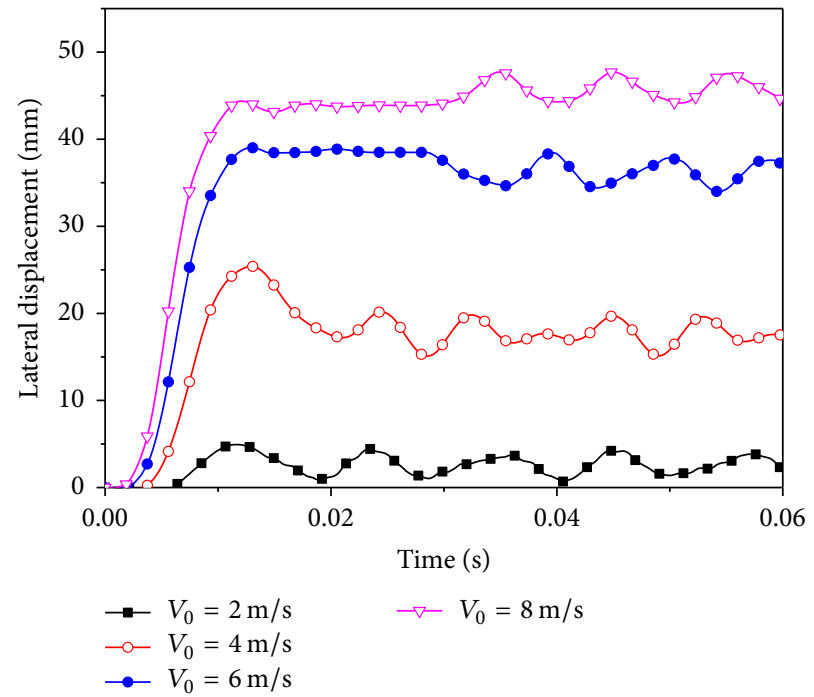

Figure 29: Lateral displacement of mid-span of beam under different impact velocities.

Table 4 shows that if the impact kinetic energy remains constant, then the residual vertical deformation of the $\mathrm{H}$ shaped steel beam and contact time decrease with the decrease in impact momentum. The transfer energy is proportional to the mass ratio whereas the mass ratio decreases with the decrease in impact momentum. Thus, the residual vertical deformation of the $\mathrm{H}$-shaped steel beam is small under low impact momentum. Figure 30 also shows that the change of the impact momentum has negligible effect in the LTB forms of the H-shaped steel beam. Figure 31 presents the time history curves of the lateral displacement on the beam mid-span. It can be seen that the lateral displacement decreases with the decrease in impact momentum. Under constant impact kinetic energy and varying impact momentum, the maximum vertical displacement difference is only $1.6 \mathrm{~mm}$ but the maximum lateral displacement difference is $7.7 \mathrm{~mm}$ as shown in Table 4 and Figure 31. This is because the LTB deformation is governed by the lateral displacement compared to vertical displacements. Based on the discussion above, it is conducted that the impact momentum is not a deciding factor for the LTB of the $\mathrm{H}$-shaped steel beam under transverse impact.

\section{Conclusion}

Through drop weight impact test, it is found that the narrow rectangular cross-section steel beam under transverse impact leads to LTB. The numerical simulation results are consistent with experimental results, which means that the 


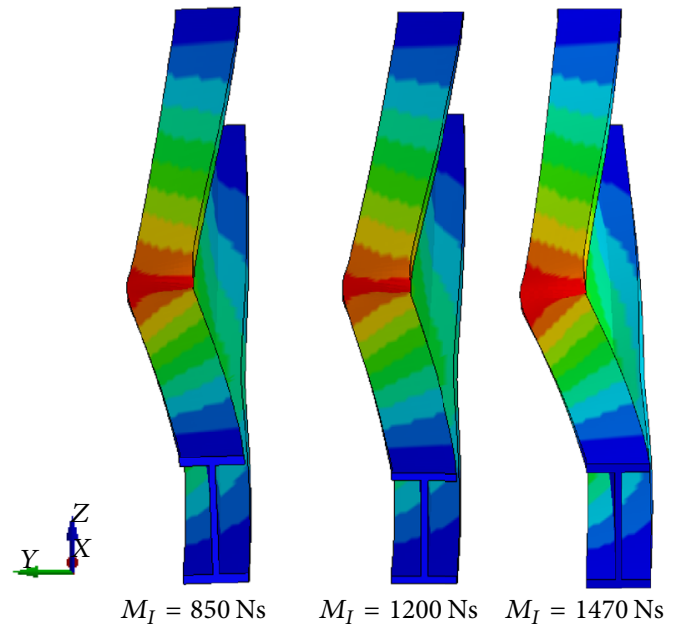

Figure 30: Plastic deformation of beam under different impact momentums.

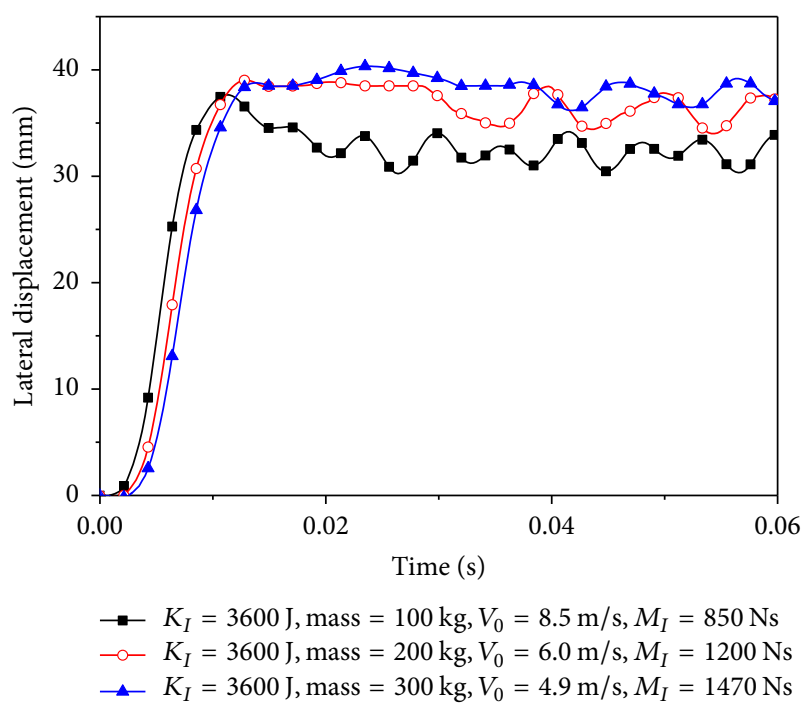

FIGURE 31: Lateral displacement-time history curve of mid-span of beam.

LTB behavior from the experimental test is not an accidental consequence due to structure or material defects, but the real response mode of the structure. The consistency of the numerical simulation and experiment results also shows that the FE code ANSYS/LS-DYNA can effectively simulate LTB with material and geometrical nonlinearities. On this basis, the abovementioned numerical method is used to conduct a study on LTB of H-shaped steel beams subject to transverse impact. From the results, the following conclusions are drawn:

(1) After studying the impact process, the deformation modes, lateral displacement, and strain of the $\mathrm{H}$ shaped steel beam, it can be seen that not only can the rectangular section beam under transverse impact lead to LTB, but the $\mathrm{H}$-shaped steel beam under transverse impact also easily causes LTB accompanied by the local deformation of the top flange.

(2) The LTB of the H-shaped steel beam under transverse impact is primarily dependent on the level of impact kinetic energy. With the increase in impact kinetic energy, the $\mathrm{H}$-shaped steel beam subject to transverse impact is more prone to LTB and local deformation.

(3) If the impact kinetic energy remains constant, then the plastic deformation of the $\mathrm{H}$-shaped steel beam and contact time increase with the increase in impact momentum whereas different impact momentum has a minor effect on LTB of the H-shaped steel beam under transverse impact.

\section{Conflicts of Interest}

The authors declare that they have no conflicts of interest.

\section{Acknowledgments}

This work is supported by the National Natural Science Foundation of China (Grant nos. 10872117, 11272189, 11672165, and 51208289).

\section{References}

[1] J. Chen, Stability of Steel Structures Theory and Design, Science Press, Beijing, China, 2014.

[2] Z. B. Xia, "The theory, experiment and calculation method on the lateral torsional buckling of Steel beam," Industrial Constructio, vol. no. 1, pp. 23-29, 1983.

[3] N. S. Trahair, Flexural-Torsional Buckling of Structures, CRC Press, London, UK, 2000.

[4] B. Yang, G. Xiong, K. Ding et al., "Experimental and numerical studies on lateral-torsional buckling of GJ structural steel beams under a concentrated loading condition," International Journal of Structural Stability \& Dynamics, vol. 16, no. 1, pp. 19-24, 2016.

[5] B. Yang, S.-B. Kang, G. Xiong et al., "Experimental and numerical study on lateral-torsional buckling of singly symmetric Q460GJ steel I-shaped beams," Thin-Walled Structures, vol. 113, pp. 205-216, 2017.

[6] M. Karmazínová, J. Melcher, and M. Horáček, “Thin-walled cold-formed steel beams with holes in lateral flexural-torsional buckling," Advanced Materials Research, vol. 743, pp. 170-175, 2013.

[7] Z. Kala and J. Valeš, "Global sensitivity analysis of lateraltorsional buckling resistance based on finite element simulations," Engineering Structures, vol. 134, pp. 37-47, 2017.

[8] M. Vild, J. Piják, J. Barnat, M. Bajer, J. Melcher, and M. Karmazínová, "Comparison of analytical and numerical methods applied to lateral torsional buckling of beams," Procedia Engineering, vol. 195, pp. 48-55, 2017.

[9] S. Kwani and P. K. Wijaya, "Lateral torsional buckling of castellated beams analyzed using the collapse analysis?" Procedia Engineering, vol. 171, pp. 813-820, 2017.

[10] A. Mohebkhah and M. G. Azandariani, "Lateral-torsional buckling resistance of unstiffened slender-web plate girders under moment gradient," Thin-Walled Structures, vol. 102, pp. 215-221, 2016. 
[11] European Committee For Standardisation, "ENV 1993-1-2, Eurocode 3: Design of steel structures. Part 1-2: General rules. Structural fire design,"Ed., Brussels, Belgium, 1995.

[12] P. M. M. Vila Real, P. A. G. Piloto, and J.-M. Franssen, "A new proposal of a simple model for the lateral-torsional buckling of unrestrained steel I-beams in case of fire: Experimental and numerical validation," Journal of Constructional Steel Research, vol. 59, no. 2, pp. 179-199, 2003.

[13] Y. Gao and F. Xi, "The lateral torsional buckling of monosymmetric cross-section steel beams under fire conditions," Chinese Journal of Applied Mechanics, vol. 30, no. 1, pp. 130-135, 2013.

[14] C. Zhang, J. L. Gross, and T. P. McAllister, "Lateral torsional buckling of steel W-beams subjected to localized fires," Journal of Constructional Steel Research, vol. 88, pp. 330-338, 2013.

[15] P. M. M. Vila Real, N. Lopes, L. Simões da Silva, and J.M. Franssen, "Lateral-torsional buckling of unrestrained steel beams under fire conditions: Improvement of EC3 proposal," Computers \& Structures, vol. 82, no. 20-21, pp. 1737-1744, 2004.

[16] N. Lopes and P. M. M. Vila Real, "Class 4 stainless steel i beams subjected to fire," Thin-Walled Structures, vol. 83, pp. 137-146, 2014.

[17] Y. Z. Yin and Y. C. Wang, "Numerical simulations of the effects of non-uniform temperature distributions on lateral torsional buckling resistance of steel I-beams," Journal of Constructional Steel Research, vol. 59, no. 8, pp. 1009-1033, 2003.

[18] C. Couto, P. Vila Real, N. Lopes, and B. Zhao, "Numerical investigation of the lateral-torsional buckling of beams with slender cross sections for the case of fire," Engineering Structures, vol. 106, pp. 410-421, 2016.

[19] R. Villavicencio and C. Guedes Soares, "Numerical modelling of the boundary conditions on beams stuck transversely by a mass," International Journal of Impact Engineering, vol. 38, no. 5, pp. 384-396, 2011.

[20] H. Wang, B. Yang, X.-H. Zhou, and S.-B. Kang, "Numerical analyses on steel beams with fin-plate connections subjected to impact loads," Journal of Constructional Steel Research, vol. 124, pp. 101-112, 2016.

[21] H. Al-Thairy and Y. C. Wang, "A numerical study of the behaviour and failure modes of axially compressed steel columns subjected to transverse impact," International Journal of Impact Engineering, vol. 38, no. 8-9, pp. 732-744, 2011.

[22] J. G. Ning, "The experimental investigation on the lateral unitability of cantilever high beams under impact loading," Mechanics and Practice, vol. 18, no. 3, pp. 34-36, 1996.

[23] J. G. Ning and Y. G. Zhao, “The experimental investigation on the lateral unitability of cantilever highbeams under impact loading," Journal of Taiyuan University of Technology, vol. 30, no. 1, pp. 11-14, 1999.

[24] W. Zhang, Numerical simulation analysis on the lateral torsional buckling behavior of steel beams under transverse impact, Shandong Jianzhu University, China, 2013.

[25] LS-DYNA, “ Keyword User's Manual,” Livermore Software Technology Corporation(LSTC), 2014.

[26] LS-DYNA, "Keyword User's Manual, Material models, II," Livermore Software Technology Corporation(LSTC), 2014.

[27] G. R. Cowper and P. S. Symonds, "Strain hardening and strainrate effect in the impact loading of cantilever beams," Tech. Rep. 28, Brown University Division of Applied Mathematics, Providence, RI, USA, 1957.
[28] R. Wang and C. Pei, "Parametric analysis of dynamic response of hot-rolled h-shaped steel beam under lateral impact load," Engineering Mechanics, vol. 30, no. s1, pp. 258-262, 2013. 


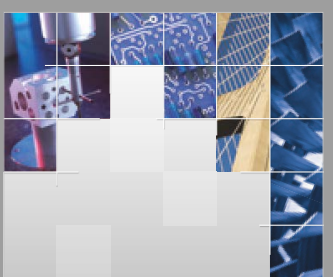

\section{Enfincering}
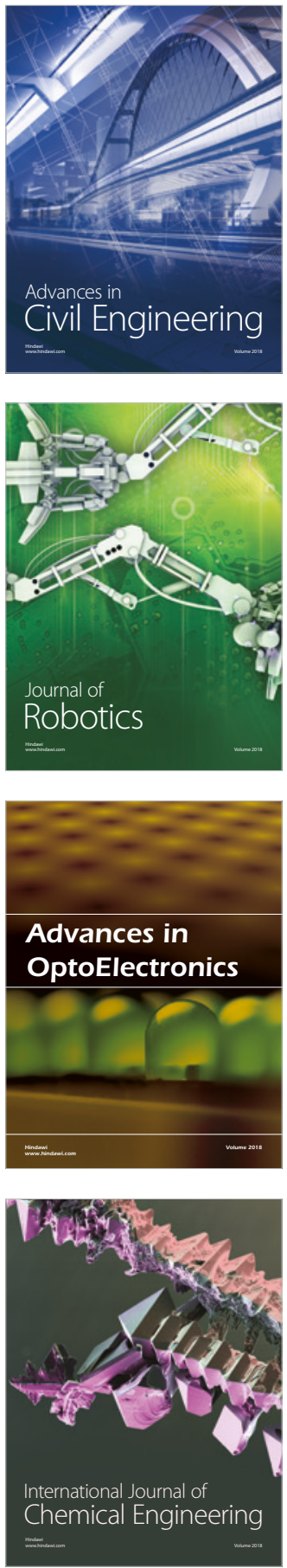

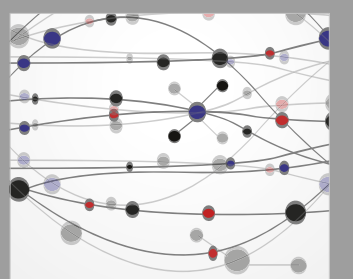

\section{Rotating \\ Machinery}

The Scientific World Journal

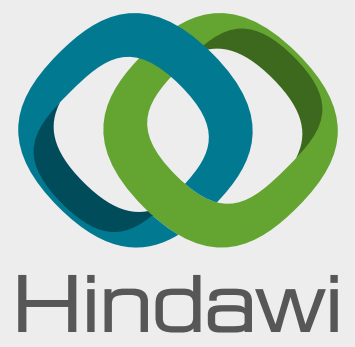

Submit your manuscripts at

www.hindawi.com
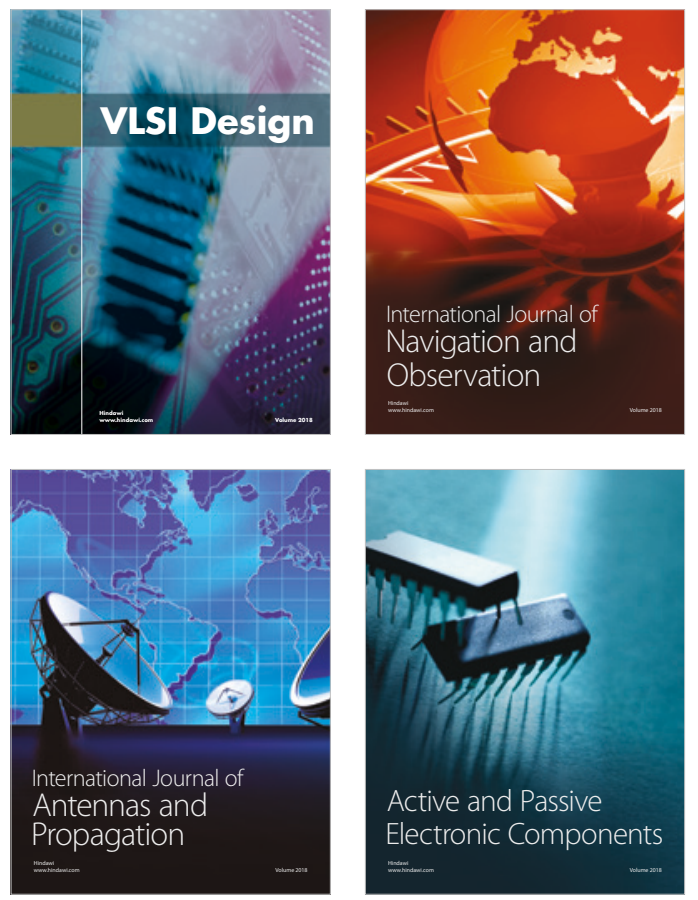
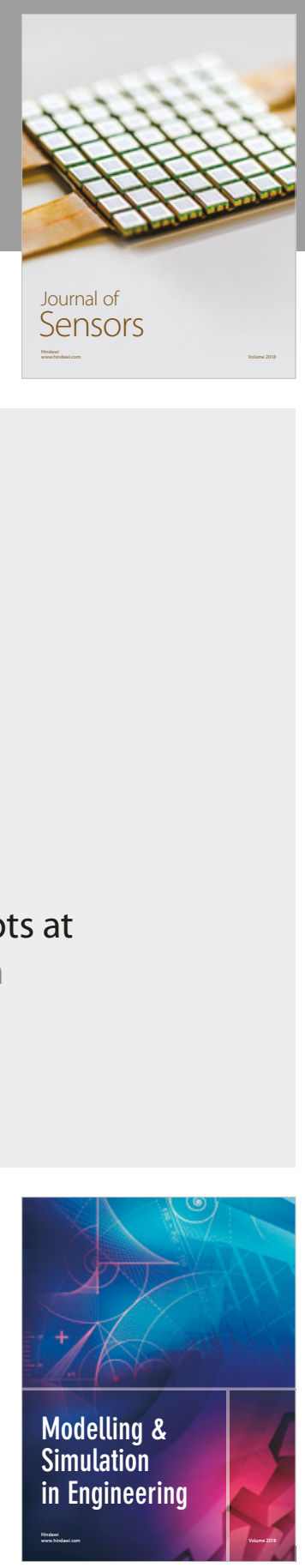

\section{Advances \\ Multimedia}
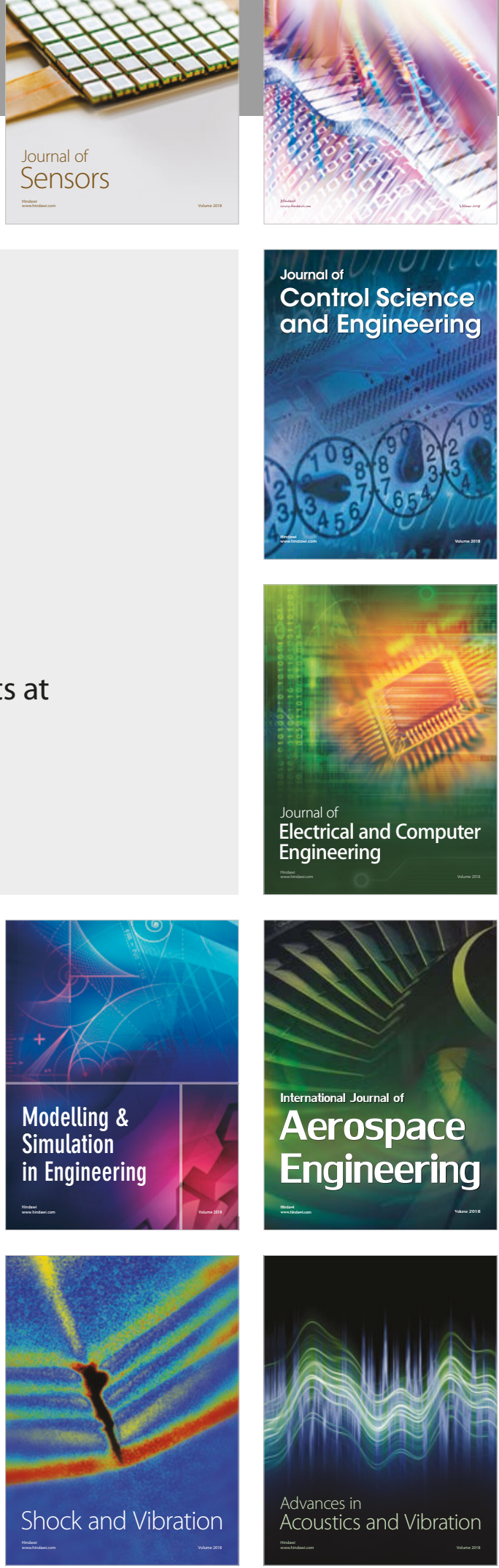